\title{
Alternatives to a table of criterion values in signal detection theory
}

\author{
ALFRED L. BROPHY \\ Behavioral Science Associates, West Chester, Pennsylvania
}

\begin{abstract}
Gardner, Dalsing, Reyes, and Brake (1984) supplied a table of criterion values $(\beta)$ related to hit and false-alarm rates in signal detection theory. Other methods of calculating $\beta$ are suggested as more accurate alternatives to using that table. A short computer program is provided to calculate $\beta$ and the sensitivity index $d^{\prime}$.
\end{abstract}

Gardner, Dalsing, Reyes, and Brake (1984) presented a table of criterion values $(\beta)$ for use with signal detection theory (Green \& Swets, 1966; Swets, 1964). The table gives two-decimal $\beta$ values for various combinations of hit and false-alarm rates. Related tables were published earlier: Elliott (1964) tabulated a measure of sensitivity $\left(d^{\prime}\right)$, another major parameter in signal detection theory; Freeman (1973) tabulated both $d^{\prime}$ and $\beta$; Hochhaus (1972) provided a table to assist in calculation of $d^{\prime}$ and $\beta$. McGowan and Appel (1977) developed APL functions to compute $d^{\prime}, \beta$, and analogous nonparametric measures.

The magnitude of $\beta$ indicates the stringency of the criterion an observer uses in deciding to report detection of a signal. High $\beta$ signifies a strict criterion; low $\beta$ signifies a lax criterion. $\beta$ can be determined from the relationship between (1) the proportion of trials in which the observer reports a signal when the signal is present (the hit rate) and (2) the proportion of trials in which the observer reports a signal when the signal is absent (the falsealarm rate). Values of $\beta$ are calculated by the equation

$$
\beta=H / F,
$$

where $H$ and $F$ are the ordinates of the standard normal distribution at the points where the tail areas of the distribution are equivalent to the hit rate and the false-alarm rate, respectively. That is, $H$ is the ordinate of the signalplus-noise distribution at the criterion, and $F$ is the ordinate of the noise-alone distribution at the criterion. Gescheider (1985, chap. 4) and Hochhaus (1972) concisely described computation of $\beta$.

To test the accuracy of the Gardner et al. (1984) table, $\beta$ values were calculated by Equation 1 using the 10 decimal values of the ordinate of the normal distribution in Pearson and Hartley (1972, pp. 153-155). Values were calculated for each pair of hit and false-alarm rates given in the table. The resulting test values were then rounded to two decimals and compared with the tabled values. Nearly $7 \%$ of the 4,950 entries in the table differed from the test values; the largest discrepancy was .03 . The er-

The author's mailing address is: Behavioral Science Associates, P.O. Box 748, West Chester, PA 19381. rors occur primarily at low levels of the false-alarm rate, but every page of the table contains some errors.

\section{ALTERNATIVES TO THE TABLE}

Although the errors in the Gardner et al. (1984) table are not crucial, accurate values are desirable. Two computer-assisted methods of calculating $\beta$ are suggested.

In the first method, the computer routine inserts appropriate ordinate values directly into Equation 1, as was done in obtaining the test values. To evaluate rates from .01 to .99 in increments of .01 (the arguments in the Gardner et al., 1984, table), 50 ordinate values must be stored. Sufficiently precise values should be used to ensure the level of accuracy desired in the $\beta$ values.

The second method neither requires storage of ordinate values, nor is limited to evaluation of rates of particular size. It estimates the standard normal deviates $(z)$ corresponding to the hit and false-alarm rates, then calculates the ordinate at each $z$ by the equation $y=$ $1 /(2 \pi)^{1 / 2} \exp \left(-z^{2} / 2\right)$, and finally applies Equation 1 to obtain $\beta$. Figure 1 shows a program, in Microsoft BASIC, that performs these calculations. The estimation of $z$ is accomplished by a portion of Beasley and Springer's (1977) approximation of the inverse normal distribution function, as proposed by Brophy (1985).

The program was tested by the method used to test the Gardner et al. (1984) table but without rounding the test values. The maximum absolute error of $\beta$ values calculated by the program was .0003 . Thus, the program deserves consideration as a more accurate alternative to the table.

The program also calculates $d^{\prime}$, which is defined as $(Z H-Z F)$, where $Z H$ and $Z F$ are the $z$-values whose lower-tail areas correspond to the hit rate and the falsealarm rate, respectively. Because the maximum absolute error of $z$-values estimated by the program is .00020 (Brophy, 1985), the values of $d^{\prime}$ have a maximum absolute error of .0004 .

Use of $d^{\prime}$ and $\beta$ assumes that the signal and noise distributions are normal and of equal variance. In the common case of unequal variance, $\beta$ is usually an adequate index of relative criterion stringency unless the rates are 
10 INPUT"HIT RATE "; H

20 INPUT"FALSE-ALARM RATE "; $F$

$30 \mathrm{P}=\mathrm{H}$ : GOSUB 80: $\mathrm{ZH}=\mathrm{Z}: \mathrm{YH}=\mathrm{Y}$

$40 \mathrm{P}=\mathrm{F}$ : GOSUB 80: $Z F=Z: Y F=Y$

50 D=ZH-ZF: PRINT"D' ="; D

$60 \mathrm{~B}=Y H / Y F:$ PRINT"BETA $="$; $B$

70 END

$80 K=-1:$ IF $P>.5$ THEN $P=1-P: K=1$

90 IF $P<1 E-05$ THEN $Z=4.3:$ GOTO 110

$100 R=S Q R(-L O G(P)): Z=(((2.321213 * R$ $+4.850141) * R-2.297965) * R-2.787189)$

$/((1.637068 * R+3.543889) * R+1)$

$110 Y=.3989423{ }^{\star} E X P(-Z * Z / 2): Z=Z \star K$ : RETURN

Figure 1. BASIC program to calculate $d^{\prime}$ and $\beta$.

extreme, but $d^{\prime}$ should be adjusted (Theodor, 1972). Other sensitivity and criterion measures (e.g., Grier, 1971; Simpson \& Fitter, 1973) are available for use with unequal variances or nonnormal distributions.

\section{REFERENCES}

Beasley, J. D., \& SPRINGER, S. G. (1977). Algorithm AS 111: The percentage points of the normal distribution. Applied Statistics, 26, 118-121.

BRophy, A. L. (1985). Approximation of the inverse normal distribu- tion function. Behavior Research Methods, Instruments, \& Computers, 17, 415-417.

Elliotr, P. B. (1964). Tables of $d^{\prime}$. In J. A. Swets (Ed.), Signal detection and recognition by human observers (pp. 651-684). New York: Wiley.

Freeman, P. R. (1973). Table of $d^{\prime}$ and $\beta$. Cambridge, England: Cambridge University Press.

Gardner, R. M., Dalsing, S., Reyes, B., \& Brake, S. (1984). Table of criterion values $(\beta)$ used in signal detection theory. Behavior Research Methods, Instruments, \& Computers, 16, 425-436.

Gescheider, G. A. (1985). Psychophysics: Method, theory, and application (2nd ed.). Hillsdale, NJ: Erlbaum.

Green, D. M., \& Swets, J. A. (1966). Signal detection theory and psychophysics. New York: Wiley.

GRIER, J. B. (1971). Nonparametric indexes for sensitivity and bias: Computing formulas. Psychological Bulletin, 75, 424-429.

HochHaus, L. (1972). A table for the calculation of $d^{\prime}$ and $\beta$. Psychological Bulletin, 77, 375-376.

McGowan, W. T., III, \& APPEL, J. B. (1977). An APL program for calculating signal detection indices. Behavior Research Methods \& Instrumentation, 9, 517-521.

Pearson, E. S., \& Hartley, H. O. (Eds.). (1972). Biometrika tables for statisticians (Vol. 2). Cambridge, England: Cambridge University Press.

Simpson, A. J., \& FitTER, M. J. (1973). What is the best index of detectability? Psychological Bulletin, 80, 481-488.

SWETS, J. A. (Ed.). (1964). Signal detection and recognition by human observers. New York: Wiley.

THEODOR, L. H. (1972). A neglected parameter: Some comments on "A table for the calculation of $d^{\prime}$ and $\beta$." Psychological Bulletin, 78, 260-261.

(Manuscript received August 20, 1985; revision accepted for publication March 27, 1986.) 